\title{
Lateral laparoscopic adrenalectomy in patients with previous abdominal surgery - single-center experience
}

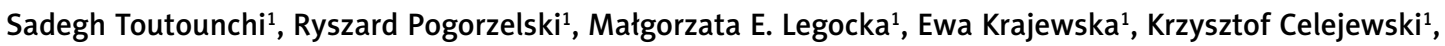 \\ Urszula Ambroziak², Zbigniew Gałązka ${ }^{1}$ \\ ${ }^{1}$ Department of General and Endocrine Surgery, Medical University of Warsaw, Warsaw, Poland \\ ${ }^{2}$ Department of Endocrinology and Internal Medicine, Medical University of Warsaw, Warsaw, Poland
}

Videosurgery Miniinv 2018; 13 (3): 283-287

DOI: https://doi.org/10.5114/wiitm.2018.77706

\begin{abstract}
Introduction: Lateral transabdominal adrenalectomy (LTA) is the most common minimally invasive technique used to treat patients with adrenal tumors.

Aim: To analyze intra-operative and post-operative complications and reasons for conversion to open surgery in patients who underwent LTA and had previous abdominal surgery.

Material and methods: Five hundred and nineteen patients underwent LTA in our center between 2005 and 2016. We identified a study group of 150 patients, with previous abdominal surgery. We analyzed the frequency of intra-operative and post-operative complications and the reasons for conversion from laparoscopic to open adrenalectomy. Results: The patients' mean age was 58; they underwent LTA due to hormonally active tumors $(n=79,53 \%)$ and non-functioning adrenal tumors $(n=71,47 \%)$. The size of adrenal lesions ranged from $20 \mathrm{~mm}$ to $90 \mathrm{~mm}$. Seventy-eight (52\%) adrenal lesions were found in the right adrenal gland, and 72 (48\%) lesions in the left adrenal gland. The mean operating time was 130 min. The mean stay in hospital was five days. The intra-operative complications included blood pressure fluctuations $(n=32)$, abnormal vascular supply of the adrenal glands causing difficulties with dissections $(n=3)$, and respiratory problems $(n=1)$. Two (1.3\%) patients had post-operative bleeding at the site of removed adrenal glands; 1 patient had an exacerbation of asthma postoperatively. Of the 150 patients analyzed, $3(2 \%)$ required conversion to open adrenalectomy. The conversions were not caused by abdominal adhesions.

Conclusions: Lateral transabdominal adrenalectomy is feasible and safe in patients with previous abdominal surgery. In our study, conversion from laparoscopic to open adrenalectomy was not caused by abdominal adhesions.
\end{abstract}

Key words: laparoscopic adrenalectomy, minimally invasive techniques, adrenalectomy after previous surgery.

\section{Introduction}

Minimally invasive adrenalectomy is the treatment of choice for most patients with benign tumors of the adrenal gland because it is associated with a shorter stay in hospital, less post-operative pain, earlier recovery, and similar long-term outcomes compared with open surgery [1-3]. Open surgery, however, seems the best treatment for some patients with adrenal cancer. Other contraindications to minimally invasive adrenalectomy are debatable [4]. Lateral transabdominal adrenalectomy (LTA) is the most common minimally invasive technique used to treat patients with adrenal tumors. Lateral transabdominal adrenalectomy may be challenging in patients with previous abdominal surgery because of post-operative peritoneum adhesions, which make it difficult to work with the equip-

\section{Address for correspondence}

Ryszard Pogorzelski MD, PhD, Department of General and Endocrine Surgery, Medical University of Warsaw, 1 a Banacha St,

02-097 Warsaw, Poland, phone: +48 502225 945, e-mail: rpogorzelski@wum.edu.pl 
ment needed for laparoscopic surgery. This problem is common because over one-third of patients who undergo laparoscopic adrenalectomy have a history of abdominal surgery [5]. However, due to conflicting evidence, we still do not know whether previous abdominal surgery is a contraindication to laparoscopic adrenalectomy. On one hand, there is evidence that previous abdominal surgery may increase the risks of operative and major post-postoperative complications [6]. On the other hand, previous abdominal operations do not increase the risk of conversion from laparoscopic to open adrenalectomy [7-9].

\section{Aim}

The aim of the study was to analyze intra-operative and post-operative complications and reasons for conversion to open surgery in patients who underwent LTA and had previous abdominal surgery.

\section{Material and methods}

Of 519 patients who underwent laparoscopic adrenalectomy in our department between 2005 and 2016, 150 had previous abdominal surgery. We retrospectively analyzed data of these 150 patients, who all underwent LTA. We analyzed the frequency of intra-operative and post-operative complications and the reasons for conversion from laparoscopic to open adrenalectomy. We collected all information by reviewing the patients' medical and operative records.

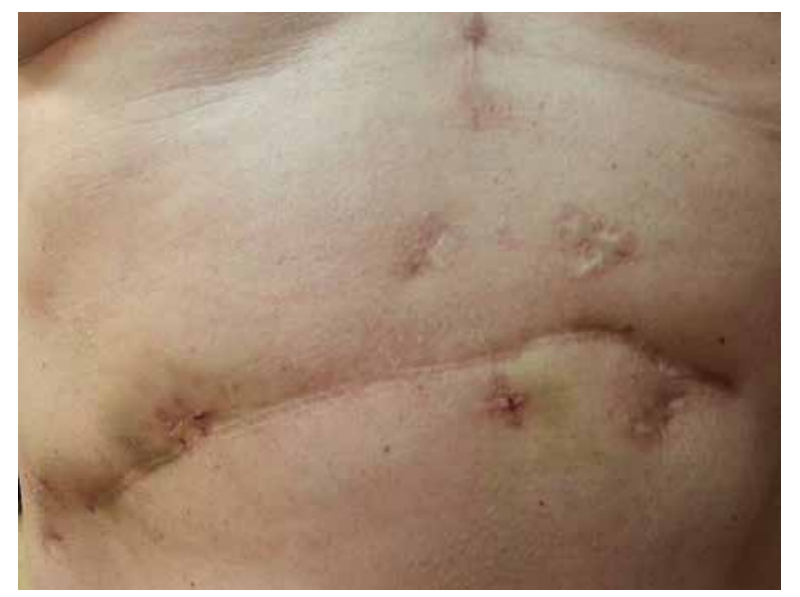

Photo 1. Location of introduced trocars during right laparoscopic adrenalectomy in a patient after previous liver transplantation and cardiothoracic surgery

\section{Surgical technique}

In all patients a team of three surgeons performed lateral transperitoneal laparoscopic adrenalectomy using 4 ports.

Each patient was placed on an operating table at a $45^{\circ}$ angle contralaterally to the adrenal gland involved. We performed mini-laparotomy (Hasson's technique), which is recommended in patients with abdominal adhesions. The first introduced $11 \mathrm{~mm}$ trocar was for the camera. Another 3 trocars were placed collaterally to the costal arch starting from the median line, placing the last one near the end of the $12^{\text {th }}$ rib, equally on the right and left side. Photo 1 presents a patient after right laparoscopic adrenalectomy with previously undergone liver transplantation and cardiothoracic surgery; all 4 trocars were introduced in a post-laparotomy scar.

In those cases, where intraperitoneal adhesions made entering other trocars impossible, we first incised the adhesions. Photo 2 presents intra-abdominal adhesions in a patient after previous open cholecystectomy. Photo 3 presents incision of intra-abdominal adhesions. In order to dissect the adrenal gland we used unipolar electrodes or atraumatic forceps with coagulation, and to obtain a sufficient operative area we used a triangular endoscopic retractor. After precise identification and dissection of the central adrenal vein we clipped it. Some additional adrenal vessels also needed to be clipped. The excised adrenal gland was removed from the peritoneal cavity in an extraction bag.

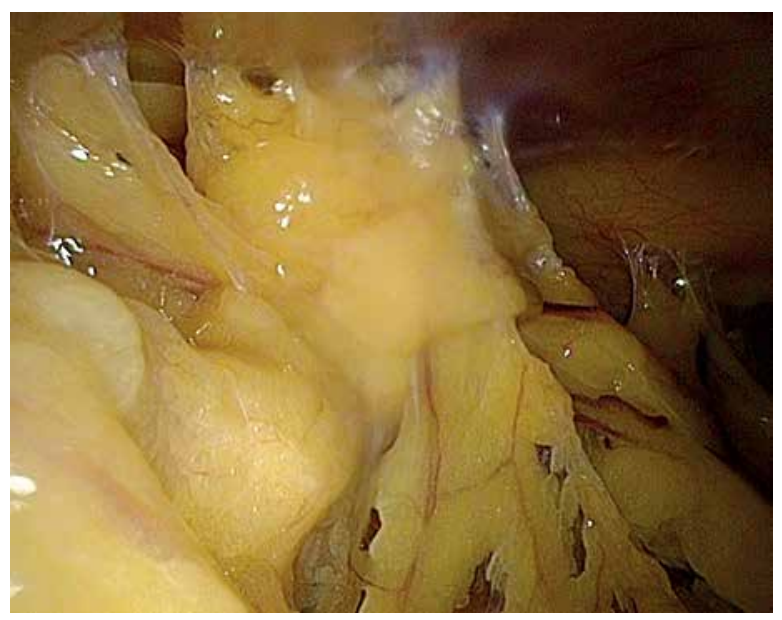

Photo 2. Intra-abdominal adhesions in a patient after open cholecystectomy 


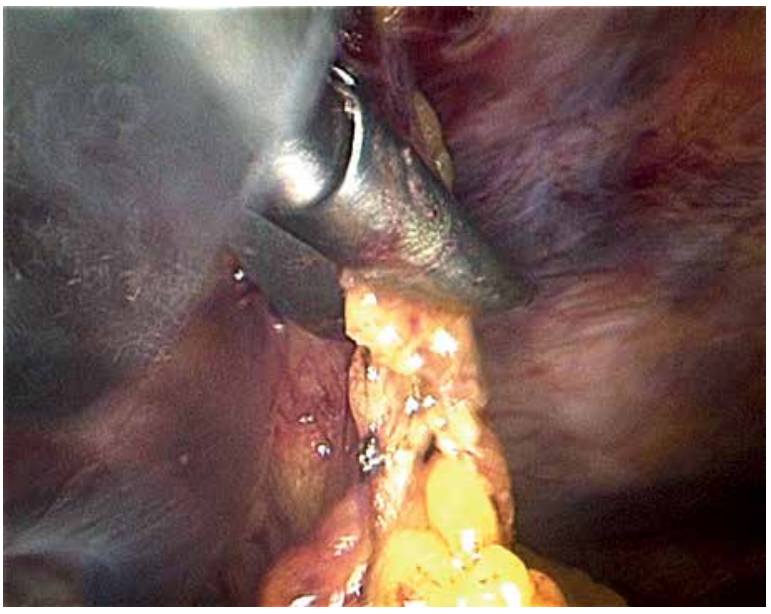

Photo 3. Incision of intra-abdominal adhesions

\section{Results}

Of 150 patients who underwent LTA and had previous abdominal surgery, 112 were women and 38 were men (mean age: 58 years; age range: $28-81$ years). The patients underwent LTA due to hormonally active tumors ( $n=79,53 \%)$; including Cushing's syndrome $(n=34)$, Conn's syndrome $(n=14)$, and pheochromocytomas $(n=21)$; the remaining 71 (47\%) patients had non-functioning adrenal tumors. The most common abdominal operations in our patients were of the biliary tract and gallbladder, appendectomy, and gynecologic operations. Table I presents all the types of abdominal operations in the analyzed patients. Forty-seven (31\%) patients had undergone more than one abdominal surgery before LTA (Table II). The size of adrenal lesions ranged from $20 \mathrm{~mm}$ to $90 \mathrm{~mm}$. Seventy-eight (52\%) adrenal lesions were found in the right adrenal gland, and 72 (48\%) lesions, in the left adrenal gland. The mean operating time was $130 \mathrm{~min}$ (range: 50-280 min). The mean stay in hospital was 5 days (range: 2-13 days). The intra-operative complications included blood pressure fluctuations especially in patients with pheochromocytoma $(n=32)$, abnormal blood vessels supplying adrenal gland tumor causing dissections' difficulties $(n=3)$, and respiratory insufficiency $(n=1)$. Two $(1.3 \%)$ patients had post-operative bleeding at the site of removed adrenal glands; laparoscopic surgery stopped the bleeding in 1 patient, but the other patient required open surgery (grade IIIb of Clavien-Dindo scale). One patient had an exacerbation of asthma postoperatively (grade II of Clavien-Dindo scale).
Table I. Type of previous abdominal operations in patients undergoing lateral transabdominal adrenalectomy

\begin{tabular}{|lc|}
\hline Type of abdominal surgery & $\begin{array}{c}\text { Number of } \\
\text { operations }\end{array}$ \\
\hline Operations of gallbladder and biliary tract & 62 \\
\hline Appendectomy & 50 \\
\hline Gynecological operations: & 49 \\
\hline Hysterectomy & 28 \\
\hline Cesarean section & 13 \\
\hline Operations of ovaries and uterine tubes & 7 \\
\hline Ectopic pregnancy - laparoscopy & 1 \\
\hline Laparotomy: & 4 \\
\hline Diagnostic & 2 \\
\hline Post-traumatic & 1 \\
\hline Splenectomy & 1 \\
\hline \begin{tabular}{l} 
Urologic procedures: \\
\hline Bricker procedure
\end{tabular} & 2 \\
\hline \begin{tabular}{l} 
Nephrectomy \\
\hline Ipsilateral nephrectomy
\end{tabular} & 12 \\
\hline $\begin{array}{l}\text { Surgical correction of ureteropelvic junction } \\
\text { obstruction }\end{array}$ & 1 \\
\hline Partial resection of ureter & 1 \\
\hline Correction of abdominal and diaphragmatic \\
hernias
\end{tabular}

Table II. Number of previous abdominal operations in individual patients

\begin{tabular}{|lc|}
\hline Number of operations in single patients & $\begin{array}{c}\text { Number of } \\
\text { patients (\%) }\end{array}$ \\
\hline One & $103(69)$ \\
\hline Two & $37(25)$ \\
\hline Three & $8(5)$ \\
\hline More than three & $2(1)$ \\
\hline Total & $150(100)$ \\
\hline
\end{tabular}


Table III. Patients who required conversion from laparoscopic to open adrenalectomy

\begin{tabular}{|lccccccc|}
\hline $\begin{array}{l}\text { Age } \\
\text { [years] }\end{array}$ & Sex & Side & Previous surgery & Conversion cause & $\begin{array}{c}\text { Operating } \\
\text { time }\end{array}$ & Histopathology & $\begin{array}{c}\text { Lesion size } \\
\text { [mm } \times \mathrm{mm}]\end{array}$ \\
\hline 56 & Female & Left & Appendectomy & $\begin{array}{c}\text { Abnormal vasculariza- } \\
\text { tion, bleeding }\end{array}$ & $3 \mathrm{~h} \mathrm{30} \mathrm{min}$ & $\begin{array}{c}\text { Adrenal cortical } \\
\text { hyperplasia }\end{array}$ & $40 \times 45$ \\
\hline 67 & Female & Right & $\begin{array}{c}\text { Open cholecystec- } \\
\text { tomy }\end{array}$ & $\begin{array}{c}\text { Cancer infiltration into } \\
\text { vena cava, resection } \\
\text { involving part of vena } \\
\text { cava }\end{array}$ & $4 \mathrm{~h} \mathrm{30} \mathrm{min}$ & $\begin{array}{c}\text { Adrenal cortical } \\
\text { carcinoma }\end{array}$ & $40 \times 25$ \\
\hline 79 & Female & Right & $\begin{array}{c}\text { Hysterectomy with } \\
\text { bilateral salpingo- } \\
\text { oophorectomy }\end{array}$ & Bleeding & $1 \mathrm{~h} 40 \mathrm{~min}$ & $\begin{array}{c}\text { Cavernous heman- } \\
\text { gioma }\end{array}$ & $30 \times 40$ \\
\hline
\end{tabular}

Of the 150 patients analyzed, only $3(2 \%)$ required conversion from laparoscopic to open adrenalectomy. The conversions were due to bleeding or diffuse tumor infiltration; the conversions were not caused by adhesions. Table III presents details of patients who required conversion to open surgery.

\section{Discussion}

In this study, we analyzed intra-operative and post-operative complications and the reasons for conversion to open surgery in patients who underwent LTA and had previous abdominal surgery. We found that both complications and conversions were uncommon. Most complications were medical and were treated successfully with appropriate medications. Moreover, the conversions from laparoscopic to open adrenalectomy were not due to abdominal adhesions and therefore seemed unrelated to previous abdominal surgery.

Currently, there are few absolute contraindications to laparoscopic surgery. They include hemodynamic instability and poor tolerance of abdominal cavity insufflation with carbon dioxide. It is not clear, however, whether previous abdominal surgery is a contraindication to LTA [10]. This is an important issue because laparoscopic adrenalectomy is nowadays the gold standard for adrenalectomy, and over one-third of patients who undergo LTA have a history of abdominal surgery [5]. Lateral transabdominal adrenalectomy has advantages over other laparoscopic techniques because it is feasible in patients with obesity or with large tumors [4]. In our department, LTA was the only technique of minimally invasive adrenalectomy used in the analyzed period. Originally, laparoscopic adrenalectomy was indicated in patients with adrenal tumors $<5 \mathrm{~cm}$ in diameter, but it is now commonly used in patients with tumors $>8 \mathrm{~cm}[11,12]$. In our study, the largest adrenal tumor removed during LTA was $9 \mathrm{~cm}$ in diameter.

Many surgeons fear that postoperative abdominal adhesions may make laparoscopic operations difficult. During LTA, Mazeh et al. found adhesions more often in patients with previous ipsilateral versus contralateral upper abdominal surgery [9]. Among patients undergoing LTA, Pędziwiatr et al. reported that dissection of abdominal adhesions was considered difficult more often in patients with previous abdominal surgery than in those without previous abdominal surgery [7]. However, in our patients, we did not find any complications related to abdominal adhesions, and none of the three conversions from laparoscopic to open adrenalectomy were due to abdominal adhesions.

The mean operating time in our study (130 min) was within the range previously reported $[6,7]$. The mean stay in hospital was 5 days, which is longer than in previous reports (about 2-4 days) [5-7, 9]. This difference may be due to different standards of post-operative care in individual institutions.

Conversion to open surgery is necessary when laparoscopic adrenalectomy is unsuccessful. Thus, the conversion rate is a measure of the difficulty of a given type of surgery. Moreover, conversion is an independent risk factor of complications in patients who undergo LTA $[13,14]$. In our study, the conversion rate was $2 \%$ (3/150); similarly, the rates of conversion from laparoscopic to open adrenalectomy, among patients with previous abdominal surgery, range from $1 \%$ to $11 \%$ in published work $[5,7,9,14]$. Similarly to earlier reports, bleeding was the most common surgical complication of LTA in our study [14, 15].

In line with previous evidence, our study suggests that LTA is safe and feasible in patients with previous 
abdominal surgery. However, when surgeons think that previous abdominal surgery may increase the risk of LTA in particular patients, posterior retroperitoneoscopic adrenalectomy (PRA) is an alternative [1]. Because PRA avoids the abdominal cavity, abdominal adhesions after previous surgery seem irrelevant to this technique. Although PRA and LTA seem to have similar effectiveness and safety [16-18], LTA is preferable in patients with larger tumors $(>8 \mathrm{~cm})$, obesity, and stage 3 or 4 renal insufficiency [10]. Moreover, most general surgeons prefer LTA over PRA because they are more familiar with LTA [19].

Our study had limitations. First, the study was retrospective, which may lead to selection bias. However, we included all patients from our centre who underwent LTA and had a history of abdominal surgery; moreover, LTA was the only technique of laparoscopic adrenalectomy used in our department in the analyzed period. Second, recording of complications was not standardized, but, as a rule, we note all clinically important complications in patients' files. Third, we included patients with all types of previous abdominal surgery, whereas some operations might be more relevant to LTA (e.g. ipsilateral cholecystectomy) than others (e.g. gynecologic operations). The small number of patients, however, made it unfeasible to compare patients with different types of previous abdominal surgery. Fourth, we did not include a control group. Because of the low frequency of the analyzed outcomes (major complications and conversions) our study seemed underpowered to detect significant differences between patients with or without previous abdominal surgery.

\section{Conclusions}

Our findings support the view that LTA is feasible and safe in patients with previous abdominal surgery. Conversion from laparoscopic to open adrenalectomy was not caused by abdominal adhesions. Future prospective studies would help to better assess the risks associated with LTA in patients with previous abdominal surgery.

\section{Conflict of interest}

The authors declare no conflict of interest.

\section{References}

1. Stefanidis D, Goldfarb M, Kercher KW, et al. SAGES guidelines for minimally invasive treatment of adrenal pathology. Surg Endosc 2013; 27: 3960-80.
2. Heger P, Probst P, Hüttner FJ, et al. Evaluation of open and minimally invasive adrenalectomy: a systematic review and network meta-analysis. World J Surg 2017; 41: 2746-57.

3. Smith CD, Weber CJ, Amerson JR. Laparoscopic adrenalectomy: new gold standard. World J Surg 1999; 23: 389-96.

4. Zacharias M, Haese A, Jurczok A, et al. Transperitoneal laparoscopic adrenalectomy: outline of the preoperative management, surgical approach, and outcome. Eur Urol 2006; 49: 448-59.

5. Morris L, Ituarte P, Zarnegar R, et al. Laparoscopic adrenalectomy after prior abdominal surgery. World J Surg 2008; 32: 897-903.

6. Seifman BD, Dunn RL, Wolf JS. Transperitoneal laparoscopy into the previously operated abdomen: effect on operative time, length of stay and complications. J Urol 2003; 169: 36-40.

7. Pędziwiatr M, Matłok M, Kulawik J, et al. Laparoscopic adrenalectomy by the lateral transperitoneal approach in patients with a history of previous abdominal surgery. Videosurgery Miniinv 2013; 8: 146-51.

8. Economopoulos KP, Phitayakorn R, Lubitz CC, et al. Should specific patient clinical characteristics discourage adrenal surgeons from performing laparoscopic transperitoneal adrenalectomy? Surgery 2016; 159: 240-8.

9. Mazeh H, Froyshteter AB, Wang TS, et al. Is previous same quadrant surgery a contraindication to laparoscopic adrenalectomy? Surgery 2012; 152: 1211-7.

10. Miller BS, Doherty GM. Surgical management of adrenocortical tumours. Nat Rev Endocrinol 2014; 10: 282-92.

11. Fiszer P, Toutounchi S, Pogorzelski R, et al. Is tumour size a contraindication to laparoscopic adrenalectomy? Case report. Videosurgery Miniinv 2012; 7: 144-6.

12. Lubikowski J, Umiński M, Andrysiak-Mamos E, et al. From open to laparoscopic adrenalectomy: thirty years' experience of one medical centre. Endokrynol Pol 2010; 61: 94-101.

13. Gaujoux S, Bonnet S, Leconte M, et al. Risk factors for conversion and complications after unilateral laparoscopic adrenalectomy. Br J Surg 2011; 98: 1392-9.

14. Thompson LH, Nordenström E, Almquist M, et al. Risk factors for complications after adrenalectomy: results from a comprehensive national database. Langenbeck's Arch Surg 2017; 402: 315-22.

15. Strebel RT, Müntener M, Sulser T. Intraoperative complications of laparoscopic adrenalectomy. World J Urol 2008; 26: 555-60.

16. Lombardi CP, Raffaelli M, De Crea C, et al. Endoscopic adrenalectomy: is there an optimal operative approach? Results of a single-center case-control study. Surgery 2008; 144: 1008-15.

17. Myśliwiec P, Marek-Safiejko M, Lukaszewicz J, et al. Videoscopic adrenalectomy - when does retroperitoneal seem better? Videosurgery Miniinv 2014; 9: 226-33.

18. Siperstein AE, Berber E, Engle KL, et al. Laparoscopic posterior adrenalectomy: technical considerations. Arch Surg 2000; 135: 967-71.

19. Kokorak L, Soltes M, Vladovic P, et al. Laparoscopic left and right adrenalectomy from an anterior approach - is there any difference? Outcomes in 176 consecutive patients. Videosurgery Miniinv 2016; 11: 268-73.

Recived: 29.03.2018, accepted: 27.06.2018. 